Provided for non-commercial research and education use. Not for reproduction, distribution or commercial use.

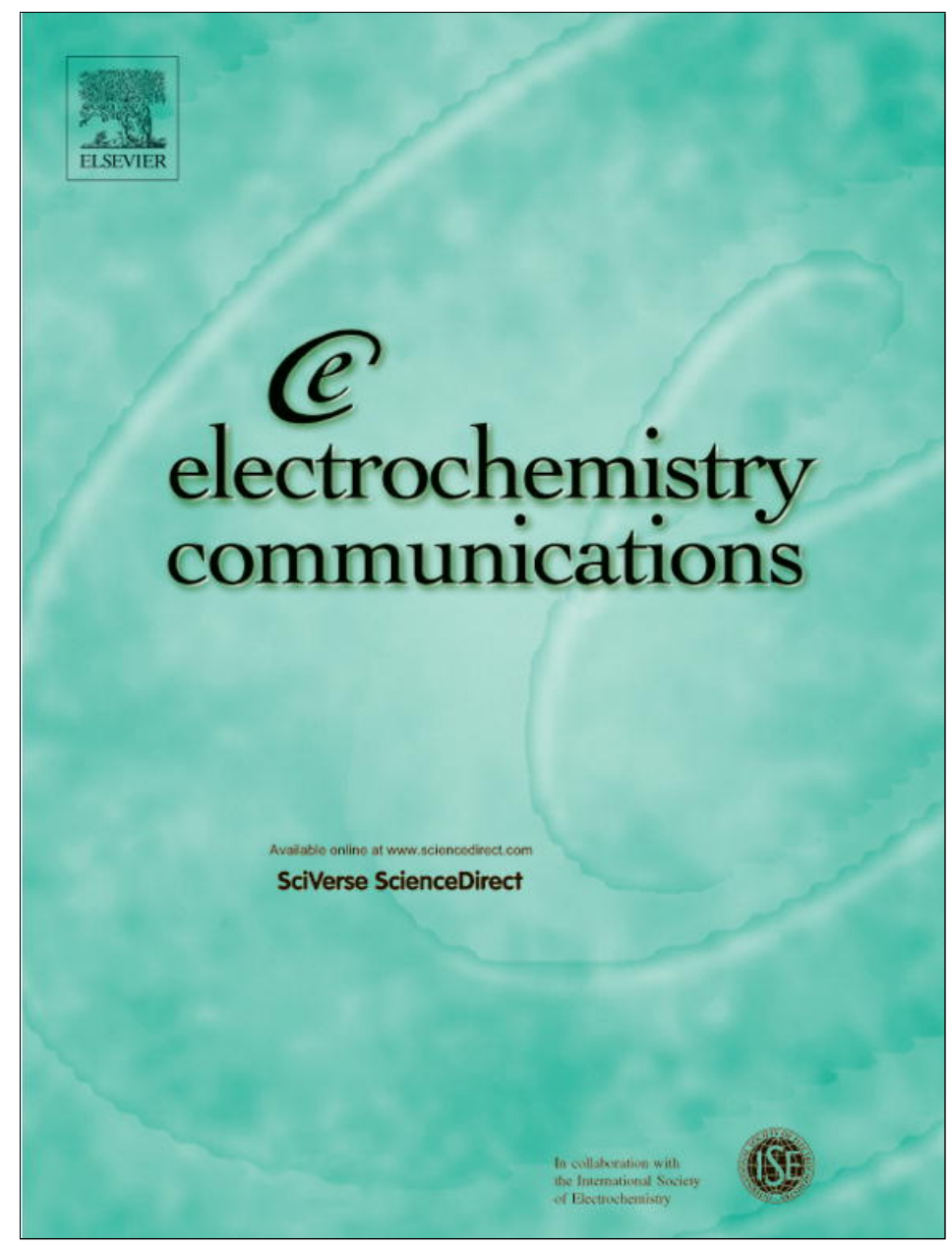

(This is a sample cover image for this issue. The actual cover is not yet available at this time.)

This article appeared in a journal published by Elsevier. The attached copy is furnished to the author for internal non-commercial research and education use, including for instruction at the authors institution and sharing with colleagues.

Other uses, including reproduction and distribution, or selling or licensing copies, or posting to personal, institutional or third party websites are prohibited.

In most cases authors are permitted to post their version of the article (e.g. in Word or Tex form) to their personal website or institutional repository. Authors requiring further information regarding Elsevier's archiving and manuscript policies are encouraged to visit:

http://www.elsevier.com/copyright 


\title{
Bismuth modified gold nanoelectrode ensemble for stripping voltammetric determination of lead
}

\author{
A. Mardegan a,b, S. Dal Borgo ${ }^{\text {c }}$, P. Scopece ${ }^{\text {b }}$, L.M. Moretto a, S.B. Hočevar ${ }^{\text {c,* }}$, P. Ugo ${ }^{\text {a,** }}$ \\ a Department of Molecular Sciences and Nanosystems, University Ca' Foscari of Venice, S. Marta 2137, Venice, Italy \\ b CIVEN, Via delle Industrie 5, 30175 Venezia-Marghera, Italy \\ ${ }^{c}$ Analytical Chemistry Laboratory, National Institute of Chemistry, Hajdrihova 19, SI-1000 Ljubljana, Slovenia
}

\section{A R T I C L E I N F O}

\section{Article history:}

Received 3 July 2012

Received in revised form 19 July 2012

Accepted 9 August 2012

Available online 18 August 2012

\section{Keywords:}

Nanoelectrode

Electrode array

Bismuth electrode

Lead

Anodic stripping voltammetry

\begin{abstract}
A B S T R A C T
The preparation of bismuth modified ensembles of gold nanoelectrodes (Bi-NEE) is described for the first time. Bi-NEEs are characterized and successfully applied for anodic stripping voltammetric measurement of trace $\mathrm{Pb}(\mathrm{II})$. Optimization of the experimental parameters provided low detection limits of $60 \mathrm{ng} \mathrm{\textrm {L } ^ { - 1 }}$ and $30 \mathrm{ng} \mathrm{L}^{-1}$ by using in-situ and ex-situ bismuth film deposition, respectively, after a 3 min accumulation step.
\end{abstract} (C) 2012 Published by Elsevier B.V.

\section{Introduction}

Since lead is a toxic element whose maximum acceptable concentration was set by the World Health Organization to $10 \mu \mathrm{g} \mathrm{L} \mathrm{L}^{-1}$, there is an increasing interest for novel, simple and reliable protocols and sensors for its determination. Among a variety of spectroscopic methods suitable for measuring trace concentrations of lead, electrochemical methods distinguish themselves for their high sensitivity and selectivity, low cost, applicability in colored, turbid as well as in high salinity water samples; moreover they are particularly suitable for on-site and decentralized analyses [1].

Concerning electrode materials, mercury has been widely used for stripping detection of trace heavy metal ions in general and for lead [2], in particular. However, due to the well-known toxicity of mercury, several alternative materials have been examined such as gold, silver, iridium, alloys, amalgams and various forms of carbon [3-5]. However, none of the above mentioned materials approached the attractive electroanalytical behavior of mercury, particularly with respect to its wide operational potential window and high overpotential for hydrogen evolution reaction. At the beginning of 2000, bismuth film electrodes (BiFEs) were introduced as an efficient replacement for mercury counterparts [6]. Bismuth electrode exhibits a cathodic part of the

\footnotetext{
* Corresponding author. Tel.: +386 14760 214; fax: + 38614760300.

** Corresponding author. Tel.: + 39041 2438503; fax: + 390412348594

E-mail addresses: samo.hocevar@ki.si (S.B. Hočevar), ugo@unive.it (P. Ugo).
}

operational potential window very similar to that of mercury, with even superior performance in the presence of dissolved oxygen. Due to its non-toxic character and excellent electroanalytical performance, bismuth electrodes have been exploited for various electroanalytical applications [7-10].

On the other hand, it is worth stressing that recent investigations [11-16] demonstrated that the electroanalytical performance of solid electrodes can be significantly improved by controlled nanostructuration of their surfaces in order to obtain the so called nanoelectrode arrays and ensembles (NEEs) $[17,18]$. The latter, firstly proposed by Menon and Martin [19], are random arrays of nanodisc electrodes, each with a diameter in the tens $\mathrm{nm}$ range, obtained typically by template deposition in track-etched microporous membranes [20]. Recently, we showed that the favorable electroanalytical performance of gold NEEs can be exploited for improving the anodic stripping voltammetric measurement of toxic elements, such as arsenic, at trace concentration levels [21]. However, on the surface of gold NEEs, the hydrogen evolution occurs at rather less negative potentials, thus narrowing the accessible potential window and precluding the detection of metal ions with re-oxidation potentials in the vicinity of hydrogen evolution [11].

Here, we combined the advantages of NEEs with those of bismuth film electrodes through modification of NEEs with bismuth films (Bi-NEE) prepared either via in-situ or ex-situ deposition protocol. These nanostructured bismuth modified electrodes were applied for the anodic stripping voltammetry of trace lead and their characteristics compared with those of bare gold NEEs and conventional Au-electrodes modified with bismuth film. 


\section{Experimental}

\subsection{Materials}

Polycarbonate filtration membranes (SPI-Pore, $47 \mathrm{~mm}$ filter diameter, $6 \mu \mathrm{m}$ filter thickness, $6 \times 10^{8}$ pores $\mathrm{cm}^{-2}, 30 \mathrm{~nm}$ nominal pore diameter, coated with polyvinylpyrrolidone) were used as templates to prepare nanoelectrode ensembles (NEEs), using an electroless plating protocol and assembled using a previously described procedure [19] and following modifications [20,22,23]. The so-called Au-macro was an Au-disk electrode embedded in Teflon. The overall geometric area of the NEE (determined by the hole in the outer insulating film $[19,20])$ and of the Au-macro is $0.07 \mathrm{~cm}^{2}$. Standard solutions of $\mathrm{Bi}(\mathrm{III})$ and $\mathrm{Pb}$ (II) (1000 $\mathrm{mg} \mathrm{L}^{-1}$ ) were from Merck, and diluted as required with $0.01 \mathrm{M} \mathrm{HCl}$.

\subsection{Apparatus}

All electrochemical measurements were carried out at room temperature $\left(22^{\circ} \mathrm{C}\right)$ using a three electrodes single compartment electrochemical cell equipped with a platinum wire as the counter electrode and $\mathrm{Ag} / \mathrm{AgCl}$ ( $\mathrm{KCl}$ saturated) as the reference electrode. A CHI440 electrochemical workstation controlled via PC was used for all anodic stripping voltammetric (ASV) measurements.

\subsection{Procedures}

ASV measurements were performed with both in-situ and ex-situ prepared Bi-NEEs in the absence of dissolved oxygen. For the in-situ protocol, the three electrodes were immersed into a $10 \mathrm{~mL}$ electrochemical cell containing $0.01 \mathrm{M} \mathrm{HCl}$ and, usually, $100 \mu \mathrm{g} \mathrm{L}^{-1} \mathrm{Bi}(\mathrm{III})$. The accumulation potential of $-1.1 \mathrm{~V}$ was applied to the working electrode in a stirred solution for $120 \mathrm{~s}$. The anodic stripping voltammogram was recorded by applying a positive-going square-wave voltammetric (SWV) scan up to $+0.3 \mathrm{~V}$ with a frequency of $25 \mathrm{~Hz}$, an amplitude of $50 \mathrm{mV}$ and a potential step of $5 \mathrm{mV}$. Prior to the next measurement, a $90 \mathrm{~s}$ conditioning step at $+0.5 \mathrm{~V}$ (while stirring) was employed to clean the substrate electrode surface.

The ex-situ preparation of bismuth film on the NEEs was carried out in $0.01 \mathrm{M} \mathrm{HCl}$ containing $1 \mathrm{mg} \mathrm{L}^{-1} \mathrm{Bi}(\mathrm{III})$ at $-1.1 \mathrm{~V}$ for $30 \mathrm{~s}$, followed by ASV measurement in $0.01 \mathrm{M} \mathrm{HCl}$ solution containing the analyte. The anodic stripping voltammogram was recorded as for the in-situ procedure. Before each measurement, a cleaning step at $-0.3 \mathrm{~V}$ for $60 \mathrm{~s}$ was performed.

\section{Results and discussion}

After a set of preliminary experiments corroborating the successful deposition of Bi-films onto NEEs, we investigated the effect of $\mathrm{Bi}$ deposition on the AS-SWV detection of $\mathrm{Pb}$ with NEEs. These tests showed that, even if the reverse component of the SWV is almost flat, there is still an advantage in using SWV instead of linear sweep voltammetry, thanks to the capability of the former to lower the background current, even with NEEs [24]. A frequency of $25 \mathrm{~Hz}$ gave a sufficiently high peak current, resolved well enough from the Bi stripping peak. Fig. 1A compares the ASV signals after 15 s accumulation at $-1.0 \mathrm{~V}$ at gold NEE in the absence (dashed line) and presence (solid line) of $1.0 \mathrm{mg} \mathrm{L}^{-1} \mathrm{Bi}$ (III) in the solution. The dashed line in Fig. 1A shows that in the absence of Bi(III), the hydrogen evolution reaction results in a large increase of the background current at potential values more negative than $-0.6 \mathrm{~V}$. On the other hand, in the presence of $\mathrm{Bi}(\mathrm{III})$, the hydrogen evolution was shifted significantly towards more negative potential values, thus considerably widening the potential window accessible with NEEs. In the anodic region, a sharp oxidation peak is observed at $-0.09 \mathrm{~V}$ that proves the extensive deposition of bismuth during the accumulation step
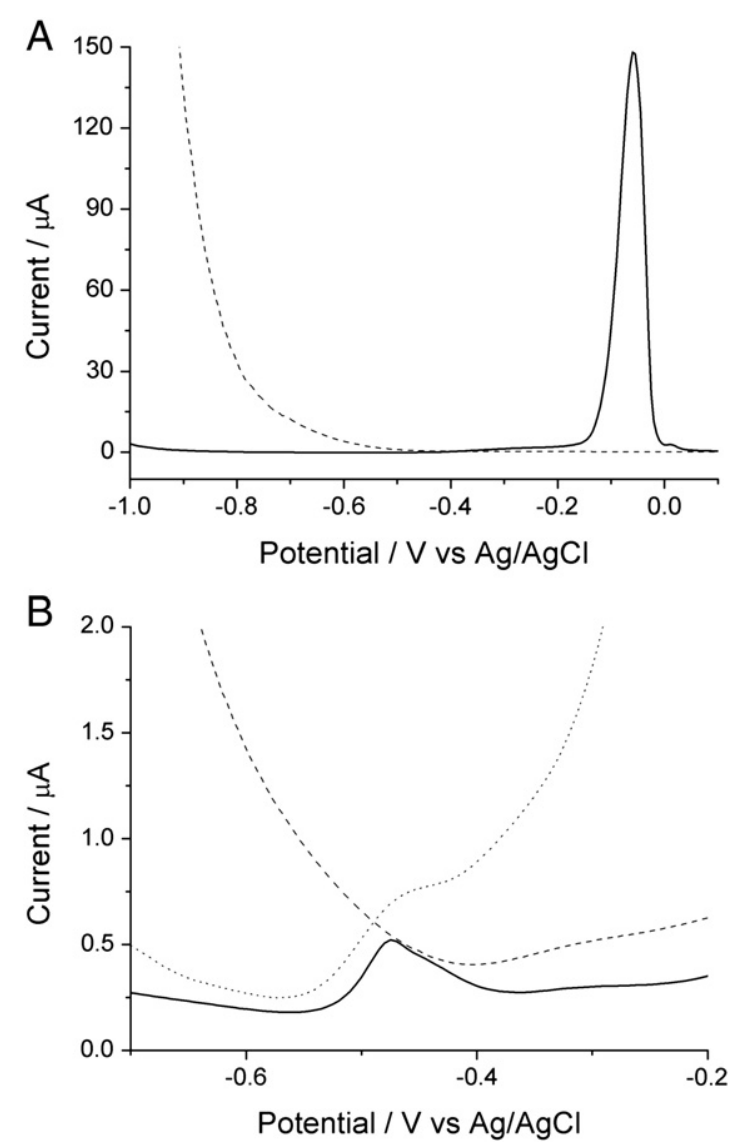

Fig. 1. (A) ASV at Au-NEEs with (solid line) and without (dashed line) $1 \mathrm{mg} \mathrm{L}^{-1} \mathrm{Bi}$ (III) in $0.01 \mathrm{M} \mathrm{HCl}$ after deposition for $15 \mathrm{~s}$. (B) ASVs in $0.01 \mathrm{M} \mathrm{HCl}^{2} 20 \mu \mathrm{L} \mathrm{L}^{-1} \mathrm{~Pb}$ (II) at the Au-macro with $1 \mathrm{mg} \mathrm{L}^{-1} \mathrm{Bi}(\mathrm{III})$ (dotted line), at bare NEE (dashed line) and at the NEE with $100 \mu \mathrm{g} \mathrm{L}{ }^{-1} \mathrm{Bi}(\mathrm{III})$ (solid line) after deposition for $120 \mathrm{~s}$. Accumulation potential: $-1.0 \mathrm{~V}$, frequency $25 \mathrm{~Hz}$, amplitude $50 \mathrm{mV}$, potential step of $5 \mathrm{mV}$.

[6]. This characteristic is similar to that observed under the same experimental conditions at the Au-macro electrode (not shown) with the main difference being the bismuth stripping peak, which was roughly one order of magnitude higher, as a consequence of a significantly larger surface of the Au-macro electrode.

Fig. 1B depicts ASVs recorded at the NEE, in the absence (dashed line) and presence (solid line) of $100 \mu \mathrm{g} \mathrm{L}^{-1} \mathrm{Bi}$ (III) in $0.01 \mathrm{M} \mathrm{HCl}$ solution containing $20 \mu \mathrm{g} \mathrm{L}{ }^{-1} \mathrm{~Pb}(\mathrm{II})$. Under these conditions, a well-defined stripping peak at $-0.47 \mathrm{~V}$ can be observed for $\mathrm{Pb}$ (II) only when $\mathrm{Bi}(\mathrm{III})$ is present in the solution. When similar measurements were performed at the Au-macro electrode (Fig. 1B, dotted line) in solution containing both $\mathrm{Bi}(\mathrm{III})$ and the analyte, significantly lower $\mathrm{Pb}$ responses were detected, confirming the effect of the nanoelectrode ensembles upon the signal enhancement.

After these preliminary measurements, we examined several operational parameters affecting the performance of Bi-NEEs. The study was focused on the use of acidic media, in order to prevent the formation of insoluble metal hydroxides [25]. Different media such as nitric, perchloric, hydrochloric acid and acetate buffer solution $(\mathrm{pH} 4.5)$ were investigated. $\mathrm{HCl}$ solution provided the highest $\mathrm{Pb}$ stripping peak current and best reproducibility. Additional experiments performed in $\mathrm{HCl}$ in the concentration range of $0.001-0.1 \mathrm{M}$ indicated that $0.01 \mathrm{M}$ $\mathrm{HCl}$ exhibited the most favorable compromise between the acidity required for metal ion analysis and the interference caused by the hydrogen evolution reaction.

Because of their small active area, the surface of NEEs can be relatively quickly saturated, therefore the optimization of bismuth concentration in the measurement solution was of crucial importance. The highest stripping signal was observed with $0.1 \mathrm{mg} \mathrm{L}^{-1}$ bismuth 
that is a bismuth concentration from one to two orders of magnitude lower than the concentration used in combination with classical glassy carbon electrodes [6]; this observation matches with the hypothesis of the saturation effect.

The optimization of the accumulation potential in the range from -1.3 to $-0.8 \mathrm{~V}$ indicated that the optimal analytical response is recorded at $-1.1 \mathrm{~V}$, whereas at more negative potentials, the attenuation of the stripping signals could be observed as a consequence of the hydrogen evolution reaction.

To provide more information on the electroanalytical performance of the Bi-NEEs, the in-situ and ex-situ Bi-film preparation protocols were compared. As shown in Fig. 2A, the in-situ prepared Bi-NEE exhibits a good linear response with $\mathrm{R}^{2}$ of 0.997 in the concentration range of 1-14 $\mu \mathrm{g} \mathrm{L}{ }^{-1}$ with $180 \mathrm{~s}$ accumulation. The calculated detection limit

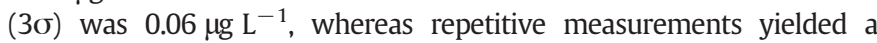
relative standard deviation of $7.10 \%(30 \mu \mathrm{g} \mathrm{L}-1, \mathrm{n}=8)$.

Fig. 2B depicts the ASVs (and corresponding calibration plot) for the ex-situ prepared Bi-NEE. This configuration unveiled electrochemical stripping characteristics similar to those of its in-situ counterpart, particularly concerning the stripping peak potential of $\mathrm{Pb}(\mathrm{II})$ and the hydrogen evolution overpotential. However, the electroanalytical performance of the ex-situ prepared Bi-NEE was markedly improved $\left(R^{2}=0.999\right)$, in the concentration range $1-8 \mu \mathrm{g} \mathrm{L}^{-1}$ with a $180 \mathrm{~s}$ accumulation step. The calculated detection limit $(3 \sigma)$ was
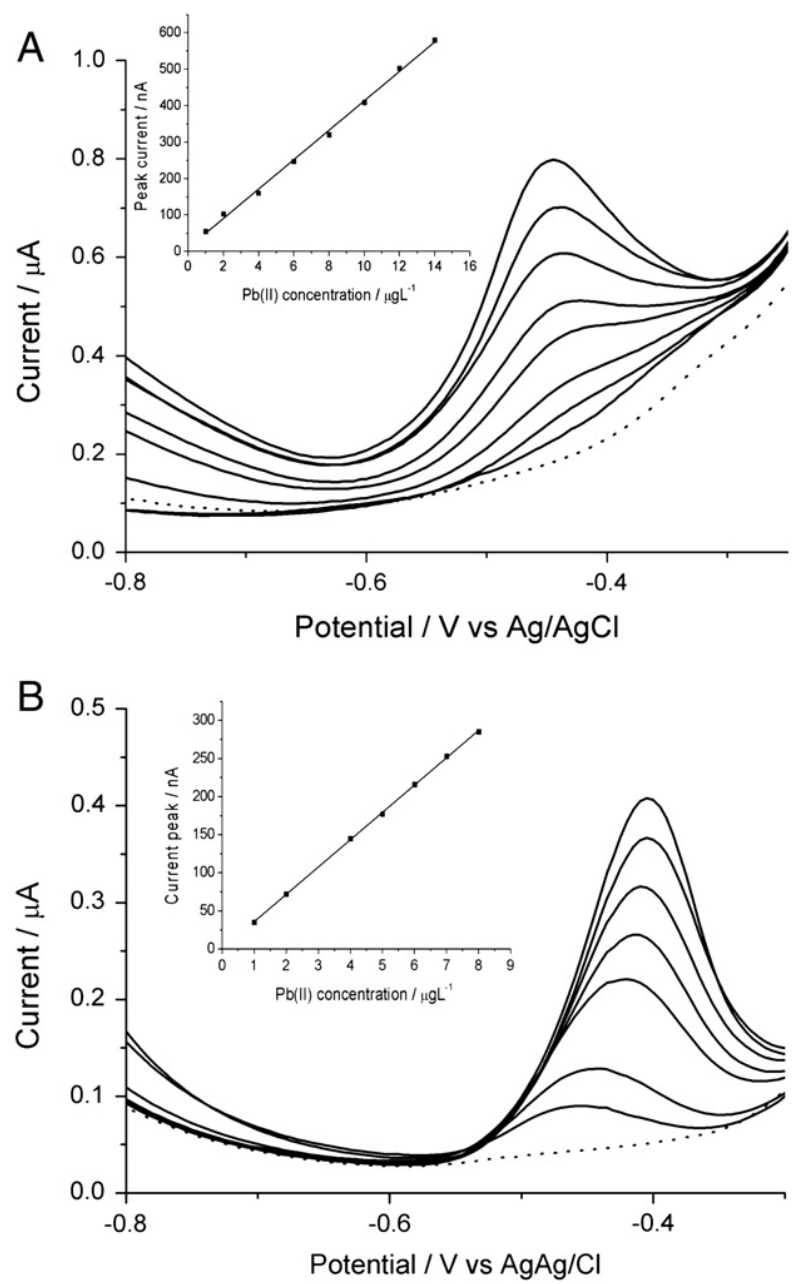

Fig. 2. (A) ASV recorded at the in-situ prepared Bi-NEE in $0.01 \mathrm{M} \mathrm{HCl}, 0.1 \mathrm{mg} \mathrm{L}^{-1}$ $\mathrm{Bi}(\mathrm{III})$ in the absence (dotted line) and presence of increasing concentrations of $\mathrm{Pb}(\mathrm{II})$, from 1 to $14 \mu \mathrm{g} \mathrm{L}^{-1}$ (full lines).(B) ASVs recorded at the ex-situ prepared $\mathrm{Bi}$-NEE in $0.01 \mathrm{M} \mathrm{HCl}$, in the absence (dotted line) and in the presence of increasing concentrations of $\mathrm{Pb}$ (II), from 1 to $8 \mu \mathrm{g} \mathrm{L}^{-1}$ (full lines). Deposition of $\mathrm{Bi}$ at $-1.1 \mathrm{~V}$ for 30 s. Insets: corresponding calibration plots. Other conditions as in Fig. 1.
$0.03 \mu \mathrm{g} \mathrm{L}{ }^{-1}$, which is 4 -times lower than the best limit previously achieved with Bi-film carbon electrodes [26].

A detailed analysis of the ASV revealed an interesting difference between the stripping patterns of the in-situ and ex-situ electrode configurations. For the ex-situ prepared Bi-NEE, the stripping peak potentials were shifted towards less negative potential values with increasing $\mathrm{Pb}(\mathrm{II})$ concentration; on the contrary, when employing the in-situ prepared configuration, the peak shifted towards more negative potentials when $\mathrm{Pb}$ (II) concentration was consecutively increased. This phenomenon can be explained with recently presented theoretical model suggesting different electrode mechanisms during the anodic stripping process, i.e. attractive forces between the deposited metal particles result in a positive shift of the stripping signal, whereas the opposite trend being observed in the case of repulsive forces [27]. The application of this model to the NEEs suggests that for the in-situ prepared Bi-NEE, i.e. when $\mathrm{Bi}$ and $\mathrm{Pb}$ are deposited together, repulsive forces are operative, while attractive forces rule the behavior of the ex-situ prepared Bi-NEE, i.e. when $\mathrm{Pb}$ is deposited over Bi.

\section{Conclusion}

We demonstrated that bismuth films can be readily deposited on the surface of gold NEEs, thus beneficially exploiting the inherent characteristics of NEEs and favorable stripping performance of bismuth film electrode. This modification allows sensitive detection of trace $\mathrm{Pb}(\mathrm{II})$ in combination with relatively short accumulation times. Preliminary studies based on the comparison between the in-situ and the ex-situ preparation of the Bi-NEEs indicated that the latter approach yielded improved electroanalytical performances. The observed shifts of the stripping peaks associated with increasing the concentration of the analyte agree with a theoretical model taking into account the role of interaction forces between the deposited metals.

\section{Acknowledgments}

This work was supported financially by MIUR-Rome (PRIN2008 MWHCP2), Regione Veneto (RESMIA) and the Slovenian Research Agency (P1-0034).

\section{References}

[1] J. Wang, Analytical Electrochemistry, John Wiley \& Sons, Inc., 2006.

[2] T.M. Florence, Journal of Electroanalytical Chemistry 27 (1970) 273.

[3] M.A. Nolan, S.P. Kounaves, Analytical Chemistry 71 (1999) 3567.

[4] Ø. Mikkelsen, S.M. Skogvold, K.H. Schrøder, M.I. Gjerde, T.A. Aarhaug, Analytical and Bioanalytical Chemistry 377 (2003) 322.

[5] I. Švancara, M. Matoušek, E. Sikora, K. Schachl, K. Kalcher, K. Vytřas, Electroanalysis 9 (1997) 827.

[6] J. Wang, J. Lu, S.B. Hocevar, P.A.M. Farias, B. Ogorevc, Analytical Chemistry 72 (2000) 3218 .

[7] E.A. Hutton, S.B. Hočevar, L. Mauko, B. Ogorevc, Analytica Chimica Acta 580 (2006) 244.

[8] E.A. Hutton, S.B. Hočevar, B. Ogorevc, M.R. Smyth, Electrochemistry Communications 5 (2003) 765.

[9] A. Krolicka, A. Bobrowski, Electrochemistry Communications 6 (2004) 99.

[10] A. Krolicka, R. Pauliukaite, I. Svancara, R. Metelka, A. Bobrowski, E. Norkus, K. Kalcher, K. Vytras, Electrochemistry Communications 4 (2002) 193.

[11] B. Brunetti, P. Ugo, L.M. Moretto, C.R. Martin, Journal of Electroanalytical Chemistry $491(2000) 166$

[12] S.P. Mucelli, M. Zamuner, M. Tormen, G. Stanta, P. Ugo, Biosensors and Bioelectronics 23 (2008) 1900.

[13] L. Cao, P. Yan, K. Sun, D.W. Kirk, Electroanalysis 21 (2009) 1183.

[14] P. Ugo, L.M. Moretto, M. Silvestrini, F.C. Pereira, International Journal of Environmental and Analytical Chemistry 90 (2010) 747.

[15] D.W.M. Arrigan, Analyst 129 (2004) 1157.

[16] P. Ugo, L.M. Moretto, F. Vezzà, ChemPhysChem 3 (2002) 917.

17] T.J. Davies, R.G. Compton, Journal of Electroanalytical Chemistry 585 (2005) 63.

[18] L.M. Moretto, M. Tormen, M.D. Leo, A. Carpentiero, P. Ugo, Nanotechnology 22 (2011) 185305

[19] V.P. Menon, C.R. Martin, Analytical Chemistry 67 (1995) 1920.

[20] P. Ugo, L.M. Moretto, in: C. Zoski (Ed.), Handbook of Electrochemistry, Elsevier, Amsterdam, 2007, ch. 16.2. 
[21] A. Mardegan, P. Scopece, F. Lamberti, M. Meneghetti, L.M. Moretto, P. Ugo, Electroanalysis 24 (2012) 798.

[22] M.D. Leo, F.C. Pereira, L.M. Moretto, P. Scopece, S. Polizzi, P. Ugo, Chemistry of Materials 19 (2007) 5955

[23] M. Silvestrini, P. Schiavuta, P. Scopece, G. Pecchielan, L.M. Moretto, P. Ugo, Electrochimica Acta 56 (2011) 7718
[24] L.M. Moretto, N. Pepe, P. Ugo, Talanta 62 (2004) 1055

[25] A. Economou, TRAC Trends in Analytical Chemistry 24 (2005) 334

[26] G.-H. Hwang, W.-K. Han, S.-J. Hong, J.-S. Park, S.-G. Kang, Talanta 77 (2009) 1432

[27] V. Mirceski, S.B. Hocevar, B. Ogorevc, R. Gulaboski, I. Drangov, Analytical Chemistry 84 (2012) 4429 